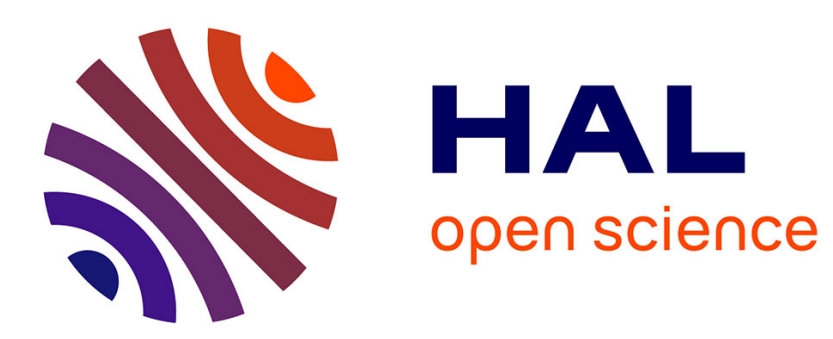

\title{
Characterization of back surface morphology for corrosion detection using patterned heat sources
}

\author{
J. Spicer, R. Osiander, L. Aamodt, J. Murphy
}

\section{To cite this version:}

J. Spicer, R. Osiander, L. Aamodt, J. Murphy. Characterization of back surface morphology for corrosion detection using patterned heat sources. Journal de Physique IV Proceedings, 1994, 04 (C7), pp.C7-59-C7-62. 10.1051/jp4:1994715 . jpa-00253208

\section{HAL Id: jpa-00253208 https://hal.science/jpa-00253208}

Submitted on 1 Jan 1994

HAL is a multi-disciplinary open access archive for the deposit and dissemination of scientific research documents, whether they are published or not. The documents may come from teaching and research institutions in France or abroad, or from public or private research centers.
L'archive ouverte pluridisciplinaire HAL, est destinée au dépôt et à la diffusion de documents scientifiques de niveau recherche, publiés ou non, émanant des établissements d'enseignement et de recherche français ou étrangers, des laboratoires publics ou privés. 


\title{
Characterization of back surface morphology for corrosion detection using patterned heat sources
}

\author{
J.W.M. Spicer, R. Osiander, L.C. Aamodt and J.C. Murphy
}

The Johns Hopkins University, Applied Physics Laboratory, Laurel, MD 20723-6099, U.S.A.

\begin{abstract}
Characterization of back surface roughness is investigated for specimens exhibiting corrosion and for prepared samples with milled channels of varying geometry. An area heating source is used initially to provide one-dimensional heating of the specimen which allows plate thinning, disbonding, or presence of corrosion to be rapidly detected. A focused heating source is then used to characterize the suspect regions through the interaction of lateral heat flow with back surface roughness.
\end{abstract}

\section{INTRODUCTION}

Thermographic nondestructive evaluation techniques have been shown to be useful in locating subsurface damage in aging aircraft [1]. While variations in the surface temperature distribution can be accurately imaged, the task of determining the nature of the subsurface structure giving rise to a particular temperature pattern remains, especially when the corrosion is on the back surface and is not detectable by visual inspection of the front surface. Of particular interest is determining whether a thermal signature can be identified which discriminates between the presence of corrosion and the simple thinning of the specimen or the presence of a disbond at a lap joint. Cross-sectional analysis of corrosion specimens shows a localized structure which is very rough with regions of pits and crevices as shown in Fig. 1. This rough structure serves to impede lateral heat flow in the specimen. A thermal characterization method is developed here which is sensitive to variations in the roughness scale on the back side of specimens of aluminum sheet.

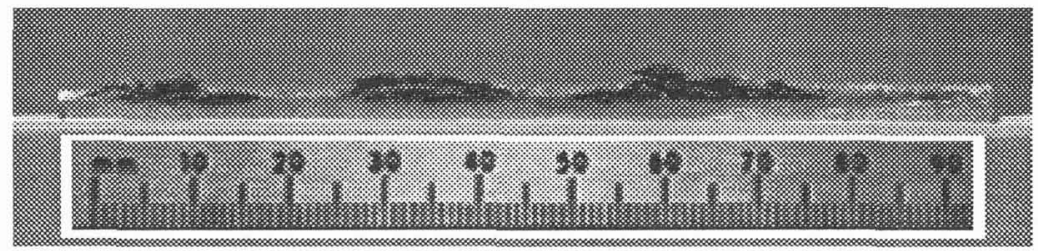

Figure 1 Cross-sectional view of $3 \mathrm{~mm}$ thick plate of 2024-T3 aluminum after 210 hours of exposure to solution of $\mathrm{NaCl}, \mathrm{KNO}_{3}$ and $\mathrm{HNO}_{3}$ as per ASTM G34-90 "Standard Test for Exfoliation Susceptibility". Note the localized nature of the corrosive attack which produces a characteristic roughness on the corroded surface. 
Central to the TRIR technique [2,3] is the analysis of the temperature-time signatures at various locations as a step-heating pulse is applied to the structure. A technique for characterization of corroded regions is proposed which implements both area and localized heating approaches. The area heating source provides one-dimensional heating of the specimen and allows suspect areas to be rapidly detected. A localized heating source is then used to characterize the defect regions. Significant lateral heat flow occurs for a localized heating source and this feature can be used to identify regions of back surface roughness which are indicative of corrosive action on the underside of the specimen.

Previous experiments on specimens with milled back-surface defects have shown that the TRIR method can image the loss of sample thickness and that the amount of remaining thickness can be calculated from the thermal transit time [4]. It has also been shown that the presence of corrosion product in 2024-T3 Al provides sufficient thermal effusivity mismatch for detection by TRIR and that second layer corrosion can be detected when a sealant material is present at the lap joint. In addition, corrosion can be detected on the back surface of an aluminum plate free standing in air and some earlier experimental evidence suggests that both the presence of corrosion product and morphology changes at the aluminum-corrosion layer interface affect the TRIR temperature-time signature [5]. We extend our earlier investigations to identify temperature-time signatures which are indicative of the presence of this rough back surface structure.

\section{EXPERIMENTAL}

\subsection{Time-Resolved Infrared Radiometry}

The TRIR technique is distinguished from other pulsed thermography techniques [6] in that the specimen surface temperature is monitored on the heating side rather than on the cooling side of the heating pulse. The step-heating approach enables the both the defect depth and its thermal mismatch with the surrounding material to be determined in a single measurement without the need for a calibration measurement made on a defect-free region of the specimen. Also, since the shape of the temperature-time curve and not its absolute magnitude provides quantitative information about the defect depth and thermal mismatch, the technique is insensitive to spatial variations in emissivity and optical absorption. Information on emissivity and absorption can be obtained from the slope of the early-time portion of the temperature-time signature. Finally, since heat is continuously applied to the specimen at low power, the temperature rise produced with this method need not be more than a few degrees. This is in contrast to pulsed techniques which deposit large amounts of energy in the sample in a short pulse with correspondingly high temperature excursions at the end of the pulse. These excursions can be large enough to damage the sample.

\subsection{Detection of Back Surface Corrosion}

Figure 2 shows the temperature-time signatures for a $2.5 \mathrm{~mm}$ thickness of 2024-T3 aluminum for three different cases: (1) never corroded, (2) corroded, and (3) corroded with corrosion product removed. The corrosion was produced in the laboratory by subjecting the specimen to a solution of $\mathrm{NaCl}, \mathrm{KNO}_{3}$ and $\mathrm{HNO}_{3}$ as specified in ASTM G34-90 "Standard Test Method for Exfoliation Corrosion Susceptibility in 2XXX and 7XXX Series Aluminum Alloys". This data was acquired with a 128x128 InSb focalplane array and a 10x10 pixel averaging procedure has been performed on all of the data sets to obtain the high temperature sensitivity.

Some of the signal increase of the corroded response over the non-corroded response may be due to the fact that the corroded region has experienced a loss of skin thickness and the thermal transit time before reaching the air interface at the back of the sample would be shorter, thus producing a greater temperature rise for a given measurement time. However, measurements of the remaining thickness of material after the corrosion product was removed showed that the amount of material lost in the specimen ranged between 0 and $8 \%$. It appears that the change in the surface morphology is the most important factor determining the temperaturetime response. This was further supported by the observation that the signal increase when corrosion is present is greater when smaller laser heating beam diameters are used. Since a rough back interface is expected to provide a greater impediment to lateral heat flow than a smooth back surface, the lateral heat flow response can be used as an indicator for the presence of corrosion which produces such an irregular interface. 


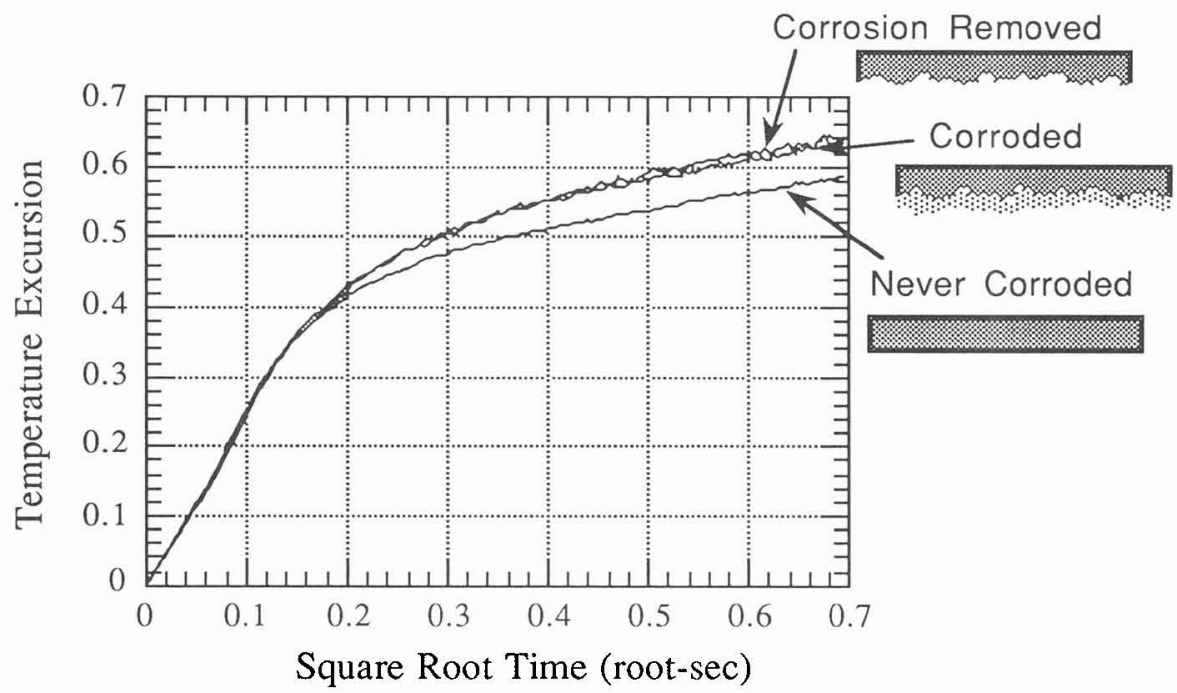

Figure 2 Temperature-time signatures for $2.5 \mathrm{~mm}$ plate of 2024-T3 with regions with corrosion, with corrosion removed and never corroded.

Note that the temperature-time response for regions with corrosion on the back face is higher than the response for regions with no corrosion on the back face. When the corrosion product was removed, the response was higher still. When the corrosion product was removed, the resulting aluminum-air interface provided a greater thermal reflection than when the corrosion product was present, and as a result the temperature of the front surface of the aluminum rose higher. Similar results were also obtained for aluminum thicknesses of 1.5 and $3.5 \mathrm{~mm}$.

\subsection{Lateral Heat Flow Variations in Milled Test Specimens}

The results in Fig. 2 demonstrate a sensitivity of the TRIR method to the morphology of a corroded surface on the back side of a specimen. In order to provide a more controlled variation to better investigate the effects observed with the corroded specimens, a number of 2024-T3 test specimens were prepared with different configurations of back surface structure. A series of channels were milled at right angles to one another to provide a grid structure on the back surface. The depths and spacings of these channels were varied from sample to sample. A localized laser heating beam with a diameter of $8 \mathrm{~mm}$ was used to heat the specimen on the smooth front surface and the surface temperature was monitored as a function of time at the center of the heating beam using the focalplane array.

Figure 3 shows the temperature-time responses for 3 of the specimens as described in the caption. Note that for Specimens 1 and 2, the intact area of the specimen is equal to the channel area and only the period of the roughness has been varied. In addition, the beam size was sufficient to cover at least 2 cycles at each roughness period, so that the response is not very sensitive to the position of the heating beam relative the channel locations. The temperature signature for Specimen 1 is enhanced compared to Specimen 2 showing the effect of reduced lateral heat flow caused by the greater number of vertical boundaries when the channel spacing is decreased.

\section{CONCLUSIONS}

A thermographic nondestructive evaluation technique for corrosion in aging aircraft is proposed which implements both area and localized heating sources. The area heating source provides one-dimensional heating of the specimen and allows suspect areas to be rapidly detected. A localized heating source is then used to further characterize the suspect regions by monitoring the variation in lateral heat flow produced by variations in back surface roughness which would be indicative of corrosive action on the underside of the skin. The physical basis for implementation of this technique was investigated by studying the temperaturetime signatures for a series of prepared specimens with different back surface morphologies. 


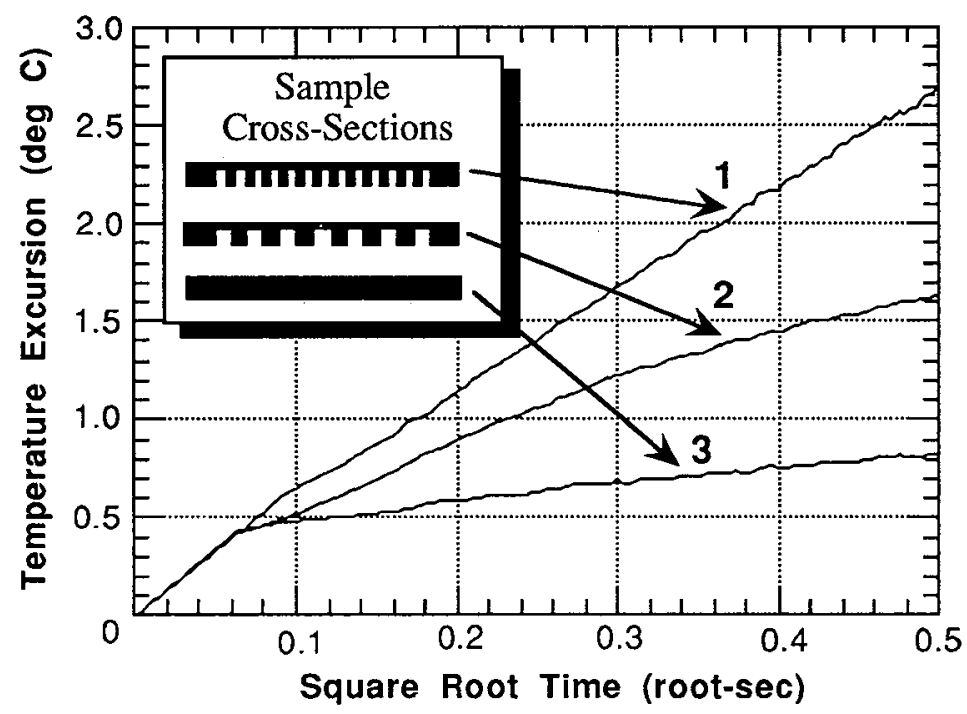

Figure 3 Temperature-time signatures for aluminum specimens with milled, back-surface grids:

1) channel width and spacing $=1.6 \mathrm{~mm}, 25 \%$ remaining thickness,

2) channel width and spacing $=3.2 \mathrm{~mm}, 25 \%$ remaining thickness,

3) solid $1.5 \mathrm{~mm}$ plate with no back surface structure.

\section{Acknowledgments}

This work was supported by the U.S. Department of the Navy under Contract N00039-89-C-5301.

\section{References}

[1] P.A. Howell, W.P. Winfree and B.S. Crews, "Numerical Simulations of Thermal Detection of Disbonds in Lap Joints," in Review of Progress in Quantitative NDE, edited by D.O. Thompson and D.E. Chimenti (Plenum Press, New York, 1991) Vol. 10, 1367-1374.

[2] J.W. Maclachlan Spicer, W.D. Kerns, L.C. Aamodt and J.C. Murphy, "Measurement of Coating Physical Properties and Detection of Coating Disbonds by Time-Resolved Infrared Radiometry," $J$. Nondestruc. Eval. 8 (1989) 107-120.

[3] L.C. Aamodt, J.W. Maclachlan Spicer, and J.C. Murphy, "Analysis of Characteristic Thermal Transit Times for Time-Resolved Infrared Radiometry Studies of Multilayered Coatings," J. Appl. Phys. 68 (1990) 6087-6098.

[4] J.W. Maclachlan Spicer, W.D. Kerns, L.C. Aamodt and J.C. Murphy, "Characterization of Hidden Airframe Corrosion by Time-Resolved Infrared Radiometry (TRIR)," in Review of Progress in Quantitative NDE, edited by D.O. Thompson and D.E. Chimenti (Plenum Press, New York, 1993) Vol. 12, 20272034 .

[5] J.W. Maclachlan Spicer, W.D. Kerns, L.C. Aamodt, R. Osiander and J.C. Murphy, "Time-Resolved Infrared Radiometry (TRIR) using a Focalplane Array for Characterization of Hidden Corrosion," in Thermosense XV, L.R. Allen, Editor, Proc. SPIE 1933(1993) 148-159.

[6] D.L. Balageas, J.C. Krapez, and P. Cielo, "Pulsed Photothermal Modeling of Layered Materials," $J$. Appl. Phys. 59 (1986) 348-357. 